\title{
Provisión, beneficio y venta de oficios americanos de Hacienda (1632-1700) ${ }^{1}$
}

\author{
Ángel SANZ TAPIA \\ Universidad de Valladolid \\ astapia@fyl.uva.es
}

Recepción: 11 de enero de 2011 / Revisión: 1 de mayo de 2011

Aceptación: 8 de junio de 2011 / Publicación: diciembre de 2011

\begin{abstract}
RESUMEN
Estudio de la provisión, beneficio y venta de los cargos de Hacienda en la América colonial española durante el siglo XVII. Análisis general del proceso de venta de estos oficios (factor, contador y tesorero de Caja Real y funcionarios de los Tribunales de Cuentas) desde su inicio hasta fin del siglo. Se describen los distintos modos de adquirir el cargo, el planteamiento legislativo de la Corona española y un estudio anual del número de provisiones, ventas, cantidades abonadas y personas titulares.
\end{abstract}

Palabras clave: Real Hacienda, Hispanoamérica colonial, venta de cargos, siglo XVII.

\section{Purveyance, Purchase and Sale of Official Posts in the Treasury of the Spanish American Colonies (1632-1700)}

\begin{abstract}
A study of the purveyance, purchase and sale of official posts in the Treasury of the Spanish American colonies during the 17th century. A general analysis of the sales processes associated with these posts (Factor, Paymaster and Treasurer of the Royal Coffers and functionaries of the Exchequer), from the beginning to the end of the century. The article describes the different ways of acquiring a position, the legal position of the Spanish Crown and an annual study of the provisions, sales, amounts paid and beneficiaries.
\end{abstract}

Keywords: Royal Treasury, Colonial Spanish America, Sale of Offices, 17th century.

SUMARIO: 1. La adquisición del oficio de hacienda. 2. La provisión de cargos de hacienda en el siglo XVII. 3. Los ingresos por oficios de hacienda. 4. Reparto por audiencias y origen de los provistos. 5. Conclusiones. 6. Referencias bibliográficas.

Dentro del sistema generalizado del beneficio y venta de cargos indianos en el siglo XVII, los oficios de real Hacienda tuvieron un tratamiento mercantil temprano porque no contaban con administración de justicia fuera de su ámbito específico y por tanto la posibilidad de su ejercicio venal no repercutía de modo directo sobre los súbditos indios ni sobre los españoles en general. Este aspecto, la capacidad de potestad judicial, que fue clave en el debate ético y jurídico sobre la provisión de cargos hispanoamericanos por dinero ${ }^{2}$, apenas afectó a la negociación pecuniaria

\footnotetext{
${ }^{1}$ Este trabajo es resultado del Proyecto de Investigación del Ministerio de Ciencia e Innovación HAR2009-10094, "Compra de cargos públicos, ejercicio del poder y redes sociales en el espacio de la Audiencia de Quito (1655-1797)".

${ }^{2}$ Parry, 1953; Tomás y Valiente, 1972, 1973 y 1976; Muro Romero, 1978.
} 
de los hacendísticos, que muy pronto se incluyeron en la dinámica comercial, más o menos controlada por el Consejo de Indias y, en última instancia, por la propia Corona ${ }^{3}$.

Los oficiales reales de la Hacienda americana formaban un grupo de la elite dirigente cuya relevancia social derivaba de ejercer una tarea fiscalizadora fundamental para la administración propiamente colonial y para los intereses hispanos en América y Europa. Como parte esencial de la Corona, el correcto funcionamiento de la real Hacienda era básico para que las riquezas americanas tuvieran allí la gestión adecuada y sobre todo el oportuno traspaso a la Hacienda peninsular, tareas en que los oficiales reales debían ser especialmente escrupulosos y responsables. De aquí la importancia de conocer cómo el nombramiento de titulares para ejercer cargos tan significativos fue afectado por el sistema de beneficios y ventas en la España de Carlos II.

Aunque las investigaciones sobre la Hacienda colonial americana del siglo XVII cuentan con muy diversos trabajos aplicados a distintos espacios y épocas, reveladores de aspectos específicos ${ }^{4}$, la adquisición por dinero de los cargos hacendísticos no está recogida ni tratada globalmente. Por ello es indudable la conveniencia de disponer de una mínima secuencia panorámica de provisiones (beneficios, ventas, remates y demás), cuantías abonadas, puestos afectados y personas implicadas, que, por encima de datos parciales, permita definir su alcance en toda Hispanoamérica e integrar su problemática en el sistema global del mercadeo de oficios americanos.

En un intento de configurar esa visión, se ofrece aquí una síntesis de la provisión general (con y sin dinero) de los cargos indianos de Hacienda desde su comienzo en 1632 hasta el final del siglo XVII ${ }^{5}$. Se describen los diversos modos de adquisición del oficio, analizando los planteamientos de la Corona y presentando los pertinentes balances cuantitativos de provisiones anuales, cantidades abonadas, reparto por audiencias e individuos titulares.

Los cargos estudiados son los denominados genéricamente "oficiales reales", es decir, factor, contador, tesorero y veedor de Caja Real (distrito fiscal de la Hacienda americana), los diversos tipos de contadores de los Tribunales Mayores de Cuentas (de cuentas, ordenador y de resultas) sitos en México, Lima y Santa Fe de Bogotá, y otros más específicos creados después, como los contadores de cuentas de Costa Firme, La Habana y Panamá, y los contadores generales de tributos y azogues de México y Bogotá. En total son 142 puestos, ocupados en varias ocasiones durante la etapa analizada.

Se tratan exclusivamente los nombramientos de propietarios efectuados por la administración central en España (Consejo y Cámara de Indias, Junta de Medios y otras especiales, e incluso validos) o por designación de autoridades indianas, adquisición en remate o transmisión legal en América, casos estos últimos que requerían la real confirmación; también se incluyen aquellas provisiones en interinidad con título del

\footnotetext{
${ }^{3}$ Para la problemática general de la venalidad en los oficios indianos vid. Pietschmann, 1982.

${ }^{4}$ Como ejemplos: Andrien, 1982; Bertrand, 1999; Escobedo, 1986; Te Paske, 1976.

${ }^{5}$ Investigación elaborada sobre los Títulos de Indias y las Relaciones de nombramientos, del Archivo General de Simancas, Dirección General del Tesoro, Inventarios 1, 13 y 24 entre otros [En adelante AGS, DGT, In-...] y Archivo General de Indias (Sevilla) [AGI abreviado], Contaduría, 235, y múltiples referencias dispersas en otras secciones de archivos y bibliografía.
} 
monarca, tuvieran o no dinero por medio. Por lo tanto, se han excluido todos los nombramientos que no contaran en algún momento de su ejercicio con el correspondiente título de oficial real, pese a que en algunos distritos fiscales se cubrían mayoritariamente los puestos mediante interinatos temporales y por tanto sin donativo añadido, como sucedía en las audiencias de Santo Domingo y sobre todo en Manila ${ }^{6}$.

\section{LA ADQUISICIÓN DEL OFICIO DE HACIENDA}

La red hacendística indiana dependía del Consejo de Indias y de las autoridades americanas, y sus espacios de actuación, es decir, las diversas cajas reales y los tribunales de cuentas, se hallaban integrados en los ámbitos de las once audiencias (incluyendo Manila) vigentes en el siglo XVII ${ }^{7}$.

Los funcionarios propios de las Cajas indianas eran los oficiales reales, es decir, contador, tesorero, factor y veedor, si bien los dos últimos unieron sus funciones, que además con frecuencia se sumaron a las de contadores y tesoreros. Su principal obligación era administrar las rentas de la Corona, ingresos y gastos, y en tareas específicas el contador controlaba cuanto entraba y salía de la caja, certificando y cuidando de los papeles y ordenando las libranzas; el tesorero fiscalizaba el tesoro, recibiendo los ingresos y haciendo los pagos que se le libraban; y el factor era el gerente de los negocios, custodiaba las mercancías del rey procedentes del pago de tributos, comercio o decomiso, y las armas y municiones, y cuidaba las ventas de los géneros reales. El veedor de fundiciones y rescates se dedicó, al desaparecer estos últimos, a cuidar lo referente a fundiciones.

En cuanto a los Tribunales Mayores de Cuentas, su función primera era la revisión de las cuentas de los distintos funcionarios de su distrito, aunque también eran auténticas audiencias en el tema fiscal y cumplían tareas de asesoramiento y decisión en todo lo referente a la hacienda indiana ${ }^{8}$. Su personal titular en un principio eran los contadores de cuentas, cuyo trabajo principal era comprobar la exactitud de las contabilidades recibidas "muy especialmente de los oficiales reales", pero como no podían realizar todo el trabajo acumulado por los constantes retrasos de las cuentas, se crearon los contadores de resultas, destinados exclusivamente a los balances atrasados. Además, como la ordenación del material era trabajo muy pesado, pues casi siempre

\footnotetext{
${ }^{6}$ Por otra parte, la numerosa presencia de funcionarios interinos (nombrados por las autoridades indianas) cubriendo plazas del real erario americano es el principal factor que dificulta la localización de las provisiones titulares, además de los frecuentes cambios de puesto o lugar de los propietarios (por interés o necesidad), los ejercicios por teniente o las cesiones y reventas sin confirmar, y no siempre es posible precisar la categoría específica ni la situación concreta de cada miembro del amplio plantel de oficiales reales.

${ }^{7}$ Para la organización de la Hacienda americana es clásico SÁnchez Bella, 1968; una reciente síntesis en Donoso, 2008.

${ }^{8}$ SÁnchez Bella, 1968, p. 66. Los contadores actuaban como verdaderos jueces con plenas competencias reconocidas por la ley. En caso de pleitos en materia de cuentas, se formaba una junta compuesta de tres oidores de la audiencia, nombrados expresamente por el Virrey, asistiendo dos contadores con voto consultivo y el fiscal.
} 
se entregaba desordenado, fue preciso incluir funcionarios específicos, surgiendo así los contadores ordenadores ${ }^{9}$.

La provisión del oficio era prerrogativa del rey (habitualmente delegada en el Consejo de Indias, la Cámara o juntas especiales), quien elegía al titular entre una terna de nombres en orden preferencial, aunque a veces le suplía una persona de confianza (valido, secretario, presidente o gobernador del Consejo). Según la ley ${ }^{10}$, los funcionarios responsables de las labores fiscales debían ser personas de valía acreditada y probada honradez, en cuya selección previa se habrían evaluado capacidad, experiencia, méritos y servicios propios y familiares ${ }^{11}$.

Pero durante el siglo XVII las crecientes y urgentes necesidades de la Hacienda peninsular determinaron que la oferta pecuniaria como donativo para ser titular de un cargo indiano se convirtiera en el servicio a la Corona más valorado que cualquier otro mérito. Así surgió el sistema de otorgar por dinero los oficios de Hacienda indiana, en principio bajo el criterio de ser concesión real por merced y después abiertamente como ventas en subasta pública.

La diferencia esencial entre beneficio y venta era la presencia de potestad judicial en el cargo negociado, existente en los casos de gobierno y justicia pero no en hacienda, Pero como no era concebible jurídica ni éticamente que la justicia se diera por dinero, entonces se calificó de beneficio al donativo aceptado, alegando que la Corona obtenía un provecho extra por el nombramiento, pero entendiendo siempre que era una merced regia, totalmente distinta de los oficios vendidos en Indias. Además, el oficio beneficiado no pasaba a la categoría de "vendible y renunciable" mientras que el vendido sí se incluía en ella ${ }^{12}$.

Por el contrario, la venta suponía transmitir la propiedad, como sucedía en los remates y subastas públicas que afectaron en Indias a los oficios de Hacienda a partir de 1654, aunque entonces la Corona continuó manteniendo el control del cargo, manifiesto en la necesidad de la confirmación regia para que la posesión resultara legal.

Un ejemplo de diferencia entre beneficio y venta de cargo de real hacienda es el caso de José de Sobrecasas y Palomares, quien benefició el cargo de contador de la caja de Popayán por sus servicios y un donativo de 2.500 pesos pero no tomó posesión porque mientras tanto el presidente de Quito había nombrado a Diego de Morales, que le había comprado en remate [venta] por 12.500 pesos. En respuesta a su recurso, la Corona dio la razón a Sobrecasas "por haber sido merced que yo [el Rey] le hice del dicho oficio, y no venta"13.

La designación en la Corte tenía su proceso específico. El aspirante presentaba al monarca su demanda con la oferta del donativo y una relación certificada de ser-

\footnotetext{
${ }^{9}$ Escobedo, 1986, pp. 61, 68 y 80.

${ }^{10}$ Sobre la real hacienda indiana, Recopilación de las Leyes de Indias, Libro VIII.

${ }^{11}$ Pese a lo cual, ya a fines del siglo XVI hay constancia de varios intentos de nombrar por dinero a los titulares de cargos de Hacienda e incluso alguna transacción, como fue la tesorería de la caja real de Lima en 12.000 pesos, hecha por el virrey García Hurtado de Mendoza (SÁnchez Bella, 1968, p. 130).

${ }_{12}$ Sobre el tema Muro Romero, 1978 y Sanz Tapia, 2009, pp. 51-85, entre otros.

${ }_{13}$ Texto en AGI, Quito, 210, L.5, fol. 285. El título de Sobrecasas, 15-VI-1683, en AGI, Contratación, 5795, L. 1, ff. 344-346.
} 
vicios y méritos propios y familiares, destacando su anterior experiencia en cuentas o papeles, si la hubiere. Habitualmente ya contaba con algún alto personaje que actuaba de valedor e intentaba asegurar el éxito de la empresa, pues en el ambiente cortesano madrileño era omnipresente la figura del agente intermediario, persona bien situada y de estrechas relaciones con el Consejo, que gestionaba papeleos, nombramientos y transacciones de los candidatos, facilitándoles informaciones y solicitudes e incluso actuando como prestamista y garante.

En consecuencia, el memorial de petición presentado al monarca iba signado del interesado y del valedor, sus respaldos económicos y de prestigio; por lo general, los patrocinadores eran, de una parte, un consejero de Indias, el propio presidente o el gobernador, y de la otra, el solicitante (si era persona notable) o en su lugar un agente, banquero o negociante, como responsable y fiador de la efectividad del pago concertado ${ }^{14}$. Notificada por decreto al elegido su elección y cumplidas por éste las condiciones pactadas, se le expedía el título correspondiente, donde se expresaban, a veces con excesivo detallismo y reiteración, los respectivos derechos y deberes del futuro oficial junto a diversos aspectos considerados de interés por una o por ambas partes.

Se especificaban, con insistente formalismo, ciertas condiciones básicas, como el abono del donativo ${ }^{15}$, las fianzas de entrega en Indias previa a la toma de posesión (teóricamente garantes del honesto ejercicio del cargo) que solían ser muy altas ${ }^{16}$, el salario (variable según la categoría de la Caja Real), el pago adelantado de la media anata (mitad en España y mitad en Indias), la normativa para el embarque y demás cuestiones prácticas. Pero sobre todo, a partir de 1654 , se puntualiza el orden en el ejercicio del cargo, pues ya entonces se dieron provisiones de puestos futuros y supernumerarios, que era preciso ajustar con los posibles nombramientos hechos por virreyes y presidentes ${ }^{17}$, por lo que las sucesiones resultaron en exceso complicadas ${ }^{18}$ y no fue extraño que el provisto en

${ }^{14} \mathrm{Su}$ actividad de mediadores se recoge en las Relaciones de beneficios, donde se les define con el término de "agentes", algunos de los cuales ejercían también de avalistas, como Diego de Villatoro, sin duda el auténtico agente por antonomasia (SANZ TAPIA, 2009, pp. 98-115).

${ }^{15}$ Para cuantías elevadas se solía pagar la mayor parte en España y el resto en Indias, como, por ejemplo, Francisco de Amilibia, con futura de tesorero de Veracruz por 5.000 pesos, pagó 3.000 en tesorería del Consejo y 2.000 en la Caja de Veracruz (AGS, DGT, In-24, 168-156).

${ }^{16}$ Oscilaban ampliamente entre 3.000 y 30.000 ducados según lugares; era frecuente añadir al título el permiso real para pagar una mitad en la península y la otra en el destino americano.

${ }^{17}$ A veces la coincidencia de varios nombramientos futurarios, suplentes o supernumerarios en un mismo cargo retrasaba o complicaba la posesión, y estos casos, junto a compras, confirmaciones, renuncias y cesiones, crearon complejos problemas para la Cámara de Indias y el físcal del Consejo. Hubo múltiples conflictos de intereses entre los mismos aspirantes o con Hacienda, como testifican abundantes litigios, por ejemplo el pleito entre Francisco Antonio Pita Castrillón y Andrés de Bustamante por la tesorería de La Plata-Potosí en 1659, donde se confrontaron el nombramiento del Consejo, la compra por remate en Indias, la existencia previa de dos futurarios y la necesidad de confirmación (AGI, Escribanía, 849B).

${ }^{18}$ Es buen ejemplo José Fernández de la Canal, aspirante a un cargo sobre cinco posibles y con varios futurarios por delante en la caja real y en el tribunal de cuentas de México, creándose un auténtico lío de sucesiones (Título en AGS, DGT, In-24, 171-174). 
España hallara en Indias su cargo ocupado y tuviera que recurrir a largos pleitos, no siempre con resultado feliz ${ }^{19}$.

Más aún, igual que sucedió años después con los cargos de gobierno y justicia, los mismos provistos fueron paulatinamente matizando las condiciones de goce o de posesión del puesto, al incluir en sus títulos ciertas cláusulas favorecedoras para sí o para posibles sucesores. El adquiriente intentaba asegurarse no sólo el ejercicio propio sino también la sucesión por muerte sin posesión, la devolución del gasto por futura no ocupada y otros imprevistos, además de determinadas mejoras (preferencia, sustitución, nombramiento de teniente, complementos del salario, etc.). Tales ajustes eran muchas veces obligados, al tratarse de una futura (provisión a la espera de puesto libre) o de un traslado, aunque también se lograron plazas para hijos menores de edad e incluso como dote para el matrimonio de las hijas ${ }^{20}$, opciones aceptadas y recogidas en la Recopilación de Leyes de Indias de 1680.

Normalmente los cargos de hacienda provistos por la Corona, ya fueran obtenidos por méritos, por dinero o por ambos valores, se concedían por la vida del provisto, según se expresaba en el título con fórmulas como "ahora y de aquí adelante cuanto mi voluntad fuere" o "es mi voluntad que vos [...] durante vuestra vida seáis", calificándose como cargo dado "en propiedad". No obstante, a veces el titular, ya ejerciendo su puesto en Indias, solicitaba licencia o potestad para designar otra persona en su lugar, nombrar teniente o conseguir mejoras, en cuyo caso la voluntad real se propiciaba mediante la oferta de otro donativo, variable desde algunos cientos a varios miles de pesos; por ello, se han incluido aquí también como provisiones estas cesiones con permiso real previa entrega del dinero pertinente ${ }^{21}$. Asimismo otro posible modo de acceso al nombramiento era por compensación de ciertas concesiones hechas a la Corona por el particular receptor del cargo ${ }^{22}$.

Por otra parte, los puestos de hacienda obtenidos en Indias provenían de un nombramiento de virrey o presidente de audiencia, que precisaba la confirmación real

${ }^{19}$ Así lo muestra la pugna por la tesorería de Guadalajara entre Francisco Cuervo y Valdés, comprador en remate por 6.000 pesos, con nombramiento del virrey y espera de confirmación, y Diego Isunza, que adquirió el cargo en la Corte por 4.000 pesos (AGI, Guadalajara, 32, N. 51)

${ }^{20}$ En el primer caso está Francisco Blas de Arnao, que benefició por 5.000 pesos en 1680 una futura de factor de la caja real de Lima para su hijo Francisco (AGI, Contaduría, 235 y también AGS, DGT, In-24, 176-64). Como dote de boda, el título de contador de la caja real de Guayaquil en 1653 a nombre de María Pérez de la $\mathrm{O}$, beneficiado en 1.500 pesos, iba destinado para quien casara con su hija (AGS, DGT, In-24, 167-367).

${ }^{21}$ Se han localizado 37 negociaciones de este tipo entre 1632 y 1700 , por un total de 83.800 pesos, destacando los 8.000 que dio Jerónimo Pardo de Lago para nombrar persona en la plaza de contador del tribunal mayor de México, y otro tanto de Juan Bautista Mendrice para nombrar contador de resultas del mismo tribunal. Pardo en AGI, Contaduría, 235 y AGS, DGT, In-24, 170-500; y Mendrice en Ibídem y AGS, DGT, In-24, 171-11.

${ }^{22}$ Tal fue el cargo de contador de cuentas del tribunal mayor de Lima (14 de abril de 1698, AGS, DGT, In-24, 173-107) para García de Híjar y Mendoza en compensación de haberse anulado sus dos futuras de presidente de la Audiencia de Santiago de Chile y de corregidor de La Paz, por las que había abonado 11.000 pesos (Ibídem y AGI, Contaduría, 235); no obstante, no ejerció la provisión de hacienda sino que la pasó a su hijo García José, quien tomó posesión en 1701, sin afectarle los reajustes que se hicieron ese año. 
para ser propietario. Pero desde la aplicación de la "Cedula de Medios" de 1654, que permitía a las autoridades americanas beneficiar estos $\operatorname{cargos}^{23}$, hubo otra doble posibilidad de obtener la provisión: mediante traspaso por renuncia del titular, o por compra en remate de subasta pública, opciones ambas con su respectiva dinámica jurídica y económica. Tales transmisiones eran bien controladas por la Corona, y aunque a veces la sucesión podía parecer una transferencia casi patrimonial entre particulares, sin embargo la Cámara de Indias siempre podía intervenir al otorgar la confirmación del cargo (aprobando el proceso de adquisición) o por la constatación de irregularidades en las transmisiones.

Si la adquisición se hacía por renuncia del propietario (dejación por vejez, enfermedad, ascenso, etc.), éste mediante documento público nombraba al sucesor, habitualmente (pero no siempre) un familiar próximo, hijo o yerno actual o incluso futuro. El así designado debía aceptar el traspaso notificándolo en la audiencia correspondiente, antes de los 70 días transcurridos desde la renuncia del titular, para ser admitido, además de demostrar que era "persona hábil" para el puesto ${ }^{24}$. Entonces debía pagar el precio que los oficiales reales precisaran tras consultar las cuantías de ventas anteriores; de esa cantidad los herederos del renunciante percibirían dos tercios o la mitad (según fuera primera o posterior renunciación del cargo) mientras que el monto restante pasaba a la Hacienda. Pero para la completa legalidad del ejercicio era preciso solicitar del rey el título correspondiente y la confirmación del cargo en un plazo máximo de seis años desde el día del remate, requisito que la Cámara concedía tras comprobar la rectitud de la transacción ${ }^{25}$.

La adjudicación mediante remate en subasta pública acaecía cuando el oficio era declarado vacante, fuera por no cumplirse alguna de las condiciones anteriores, por dejación voluntaria del titular o por ser de nueva creación. Los oficiales reales fijaban el precio legal y se procedía a pregonar la venta para que los interesados manifestaran sus ofertas y pujaran, lo que se hacía ante el edificio de la audiencia. El cargo se adjudicaba al mejor postor, decisión generada bien por la mayor cuantía ofrecida, por las mejores condiciones de pago o a veces por demostrar mejor capacitación, y su completa legalización también requería la consiguiente confirmación regia.

Como se ha dicho, los remates de puestos fiscales comenzaron a partir de la "Cédula de Medios" de 1654 y se ejecutaron bajo supervisión de las autoridades americanas. Mientras tanto, la Cámara de Indias siguió cubriendo provisiones, ameritadas

${ }^{23}$ Capítulo 14 de la Instrucción de 1-VI-1654 a las primeras autoridades americanas para los medios que se han de beneficiar en ellas con que aumentar la real hacienda. AGI, Indiferente, 4329, L. 1, ff. 183r-197v, y Muro Romero, 1978, pp. 63-64.

24 Sin embargo, en ocasiones el comprador carecía de las mínimas condiciones para ejercer, como consta en casos de minoría de edad, pero también cuando ni siquiera sabía escribir, leer o hacer cuentas; este caso fue denunciado por el virrey de México, duque de Alburquerque, cuando negó la posesión de la tesorería de la caja de Guadalajara a Nicolás de Quiñones, que la había beneficiado por 4.000 pesos, porque "no sabe escribir y no entiende ni ha manejado jamás cuenta, hacienda ni papeles". El virrey duque de Alburquerque a S.M. México, 10-VI-1655. AGI, México, 38, N.8.

${ }_{25}$ Según Tomás y Valiente (1976, p. 736) desde el remate y el pago del precio, el comprador era provisionalmente habilitado para ejercer el oficio, sin perjuicio del posterior y definitivo título y la confirmación real. 
o beneficiadas; sin embargo es notorio que en el último cuarto del siglo aumentaran las demandas de titulares para "nombrar persona" sucesora, siempre con oferta en dinero. En suma, estas provisiones presentan entonces una compleja dinámica que mezclaba múltiples factores, desde la valoración del aspirante a la situación política y económica, y a la pugna de intereses entre la Corona, las autoridades americanas y los futuros titulares.

Avanzando datos ${ }^{26}$, las provisiones de oficiales reales de hacienda indiana entre 1632 y 1700 fueron 621, de las cuales 480 correspondían a los puestos propios de cajas reales y las 141 restantes eran de tribunales mayores de cuentas y otros contadores de cuentas existentes en La Habana (para Cuba, Santo Domingo, Puerto Rico, Florida, Cumaná e Islas de Barlovento), Caracas (para Costa y Tierra Firme) y Panamá. De esas 621 provisiones, el dinero intervino en 487, mientras que 124 fueron dadas por valoración no pecuniaria y quedan 10 casos restantes por localizar.

Para analizar el modo de acceso se establecen varias categorías, por la mucha diversidad existente, porque que la mayoría de los provistos contaba con valoración meritoria ${ }^{27}$ no pecuniaria, y porque las transacciones (beneficio o venta) se hicieron en España y en Indias. Sus claves:

- SER: Sólo méritos, servicios, experiencia, etc., siempre sin dinero ${ }^{28}$. Hay localizadas 124 provisiones.

- SYB: Reúne servicios y donativo pecuniario ${ }^{29}$. Son 408 en total.

- BEN: Sólo donativo en dinero ${ }^{30}$. Solamente fueron 13.

- VEN: Sólo cargos comprados en remate y cargos procedentes de traspaso por renuncia en Indias. Se han constatado 66.

- DES: Aquellos casos aún no localizados. Suman 10.

En los porcentajes respectivos, los nombrados con presencia de dinero (aunque también contaran méritos: BEN + SYB + VEN) casi alcanzan las cuatro quintas partes del total (el $78 \%$ ) mientras los provistos sólo por servicios/méritos suponen tan sólo la quinta parte $(20 \%)$.

\footnotetext{
${ }^{26}$ Todas las cantidades, cuadros, gráficos y balances son de exclusiva elaboración del autor.

${ }^{27}$ Generalmente en los títulos de nombramiento aparece la concesión con la frase "en atención a vuestros servicios" u otra fórmula similar, seguida del donativo, pero es raro que se expliciten los méritos. Entonces, para asegurar la certeza de las prestaciones no pecuniarias se ha comprobado su presencia por otras vías documentales o bibliográficas, de modo que en la categoría "servicios" solamente están casos verificados como auténticos.

${ }^{28}$ Incluye: a) provisiones de la Corona titulares e interinas, b) nombramientos de autoridades indianas con propiedad confirmada, y c) títulos recibidos de otro propietario mediante cesión aprobada por la Corona.

${ }^{29}$ Incluye los mismos tipos anteriores pero beneficiados, junto a las provisiones de la Corona para nombrar persona sucesoria.

${ }^{30}$ Provisiones beneficiadas por la Cámara o las autoridades indianas, sin que se conozca ningún otro mérito.
} 


\section{Gráfico I}

Provisiones de real hacienda según acceso en \%

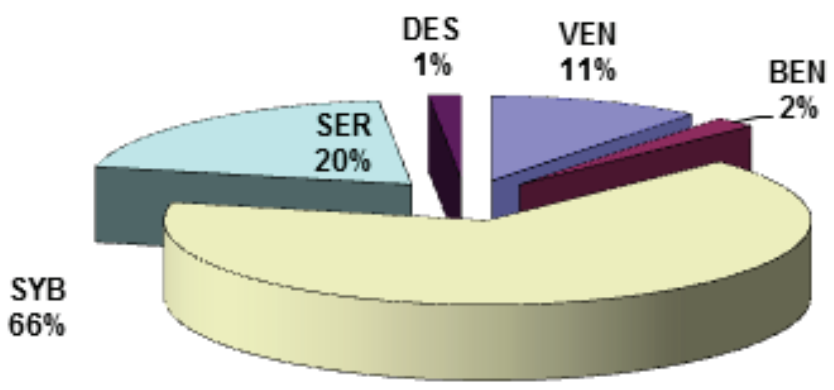

Se advierte también que casi dos tercios de las provisiones (65\%) suman méritos personales y donativo frente a esa quinta parte ameritada, y otra décima parte fue adquirida en venta; sólo un porcentaje mínimo, el $2 \%$, se benefició por dinero sin que conste ningún otro servicio. Resulta evidente la efectividad del donativo pecuniario, que permitió conseguir más de $2 / 3$ de los oficios estudiados.

Pero otra interpretación de los mismos datos ofrece una perspectiva distinta: Si se valora como única referencia la presencia de dinero resulta un $78 \%$ de provisiones negociadas, por el contrario, destacando la presencia de méritos/servicios la conclusión es opuesta, pues un $85 \%$ de casos contó con prestaciones no pecuniarias frente al $13 \%$ obtenido sólo por dinero. El mínimo porcentaje no localizado (2\%) no supone alteración significativa del resultado.

\section{LA PROVISIÓN DE CARGOS DE HACIENDA EN EL SIGLO XVII}

Según los autores citados al principio, la negociación mercantil de los oficios indianos por la Corona quedó ya inicialmente definida a partir de la real cédula de 14 de diciembre de $1606^{31}$, pero se fue desarrollando y potenciando de modo gradual en la década de 1630 al incorporarse los cargos de hacienda ${ }^{32}$, situación ampliada a partir de 1674 con los políticos o de gobierno (presidentes de audiencia, gobernadores,

${ }^{31}$ Tomás y Valiente, 1976, pp. 728-729. Texto en AGI, México, 192, N. 19, como referencia. Muro Romero (1978, pp. 1-58) sintetiza el proceso y analiza el planteamiento de anteriores investigadores.

${ }^{32}$ Otros autores citan 1633 como inicio de la venta de oficios de hacienda aunque hay datos anteriores, como el nombramiento de Domingo de Aldape por tesorero de la Caja de Zacatecas por 5.000 pesos, según título en Madrid a 12-XII-1632, AGI, Contratación, 5789, L. 1, ff. 114-116, por lo cual hemos retraído el comienzo a 1632 . 
alcaldes mayores y corregidores) y que finalmente acabó por incluir también los puestos específicamente judiciales de las audiencias indianas, de 1683 en adelante ${ }^{33}$.

Volviendo a la hacienda americana, la investigación reúne datos sobre 142 puestos de oficiales reales (cajas reales y tribunales de cuentas) entre 1632 y 1700, con un total de 621 provisiones, de las que 487 resultaron negociadas por la suma global de 2.786.258 pesos de 8 reales, 124 se otorgaron sólo por méritos y 10 se desconocen. El gráfico II muestra las provisiones anuales con dinero (DIN), ameritadas (SER) y totales (TOT):

\section{Gráfico II}

Provisiones de real hacienda (1632-1700)

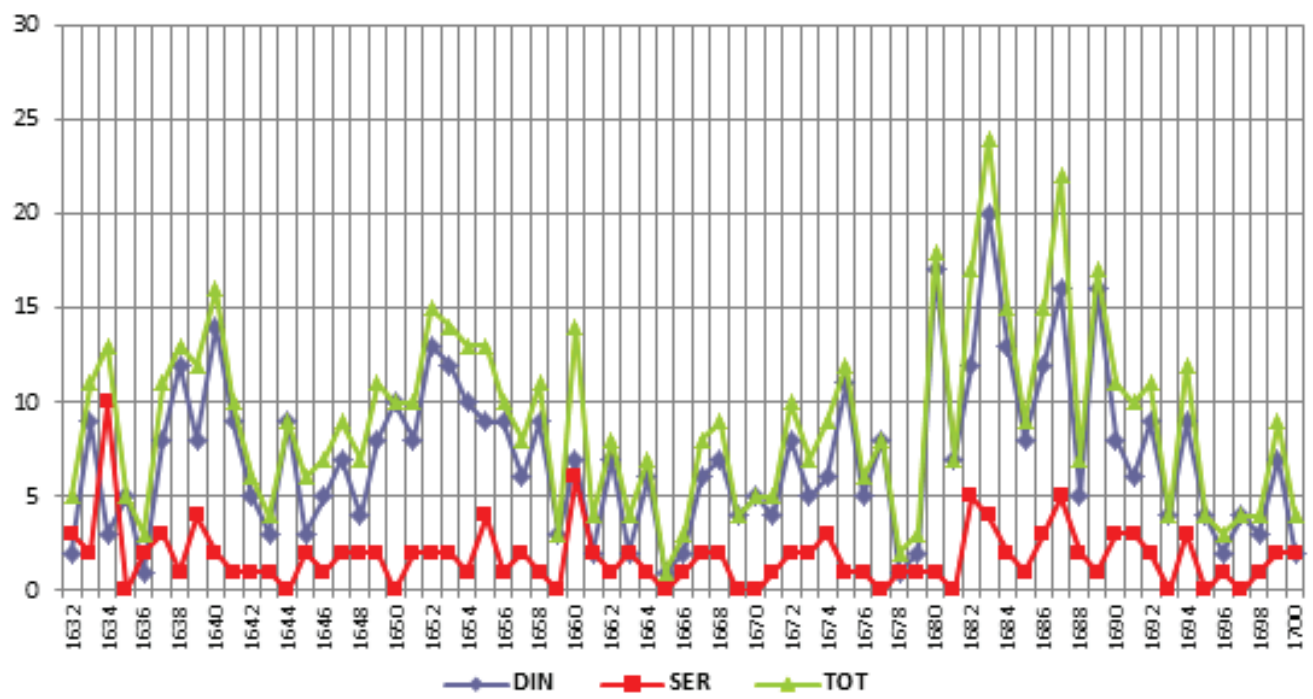

La línea de nombramientos discurre mayoritariamente paralela con las provisiones de dinero, con tres periodos de máximos destacables: Entre 1633 y 1641 (con bajada en años intermedios) en torno a 13 casos anuales; entre 1650 y 1660 (descenso en 1659) rondando los 14, y sobre todo en 1680-1689 con cifras altas (más de 15), en especial 1687 que reunió 24. Por el contrario, las etapas de mínimos son los años $34-35,59$ a $69,78-79$ y $96-98$.

El proceso de los nombramientos se divide en los siguientes bloques:

\section{a) $1^{\text {a }}$ etapa: 1632 a 1643 . Mandato del Conde Duque de Olivares}

Las primeras plazas de hacienda provistas por servicio monetario se dieron en 1632-1633 $3^{34}$ bajo el Conde-Duque, omnipotente valido de Felipe IV, y fueron 11 en

\footnotetext{
33 Sanz TAPIA, 2007, pp. 33-57.

${ }^{34} \mathrm{El}$ año de referencia corresponde al real decreto de concesión, siempre previo al abono del dinero convenido y a la expedición del título o de la confirmación, de ser ésta procedente.
} 
total, 2 de contador de tribunal de cuentas y 9 de oficiales de caja real; todas propietarias y por un monto de 61.000 pesos. Sus nombramientos no se efectuaron por el Consejo de Indias, marginado por Olivares, sino en juntas especiales creadas por él para controlar muy diversos asuntos ${ }^{35}$. El máximo organismo gubernativo indiano reaccionó con malos ojos ante la negociación a sus espaldas y así lo denunció al monarca, subrayando la necesaria idoneidad de los compradores, el daño causado a los beneméritos peninsulares y criollos sin suficientes recursos, la conveniencia de equilibrar la cantidad abonada con la remuneración propia del cargo, e incluso sugiriendo pedir más dinero por las plazas dadas a perpetuidad, además de advertir del riesgo de que los así nombrados quisieran recuperar su gasto mediante fraudes al Erario, contrabando u otras formas delictivas. No obstante, la respuesta regia justificó la iniciativa, alegando que "pudiéndolo excusar no usaré de este medio, pero la apretura de los tiempos obliga a todas estas extrañezas y [...] no se convierten en usos voluntarios sino en la defensa de la religión" ${ }^{\prime 36}$, pretexto frecuente en Felipe IV, sobreentendiendo que la fórmula favorecía a la real Hacienda sin mayores perjuicios. En décadas siguientes la vía del donativo como "beneficio" se aceptó por fórmula válida y justificable, como regalía del monarca al servicio de importantes necesidades.

Sin embargo, su puesta en práctica fue irregular y sin una legislación bien definida ${ }^{37}$ pues lo mismo se efectuaban provisiones discutibles como se marginaban iniciativas de importancia económica por ilegalidad. Es notorio el rechazo del Consejo a que las autoridades indianas gestionaran por su cuenta el asunto, pese a que ya en 1636 la Corona había recibido de ellas sugerentes propuestas que calculaban unos interesantes ingresos en torno a 100.000 pesos para engrosar las arcas de cada virreinato ${ }^{38}$.

Abierto el camino, en los diez años siguientes hasta la caída de Olivares en 1643 la Corona autorizó 109 provisiones fiscales (19 en tribunales mayores de cuentas), de las que 79 fueron mediante dinero por un importe de 388.500 pesos. El gráfico III ofrece el balance anual:

${ }^{35}$ Tales fueron la Junta de Vestir la Casa o la de Coroneles, o también por gestión de algunos subordinados, pues en 1632 el duque de Medina de las Torres se encargaba de los beneficios (KonetzKe, 1953, II, $1^{\circ}$, p. 343) y en 1640 era el conde de Castrillo, gobernador del Consejo de Indias, "en virtud de la orden y comisión que le tengo dada para el beneficio y venta de oficios y otras cosas de las Indias". AGI, Indiferente, 454, L. A23, f. 18. Como a veces el negocio se hizo mediante acuerdo privado con el comprador, el monarca pidió al Consejo títulos de nombramiento en blanco (Consulta del Consejo de Indias. Madrid, 4-IV-1642. AGI. Lima, 6), dato ofrecido por el Prof. Arrigo Amadori, al que agradezco aquí su información.

${ }^{36}$ Consulta del Consejo de Indias, 3-IV-1633, y respuesta a la misma (AGI, Indiferente, 757), citada por SCHÄFER, 2003, II, p. 168.

${ }^{37}$ Así lo analiza en detalle Tomás y Valiente, 1976.

${ }^{38}$ Hurtado de Corcuera, presidente y gobernador de Filipinas, al Rey. Manila, 30-VI-1636 (AGI, Filipinas, 7), en Muro Romero, 1978, p. 32. Similar oferta hizo en 1647 el virrey Palafox y Mendoza, al sugerir la provisión por dinero de cinco o seis alcaldías mayores novohispanas, con una ganancia de 100.000 pesos, Ibidem, p. 36, nota 61 . 


\section{Gráfico III}

Provisiones de real hacienda (1632-1643)

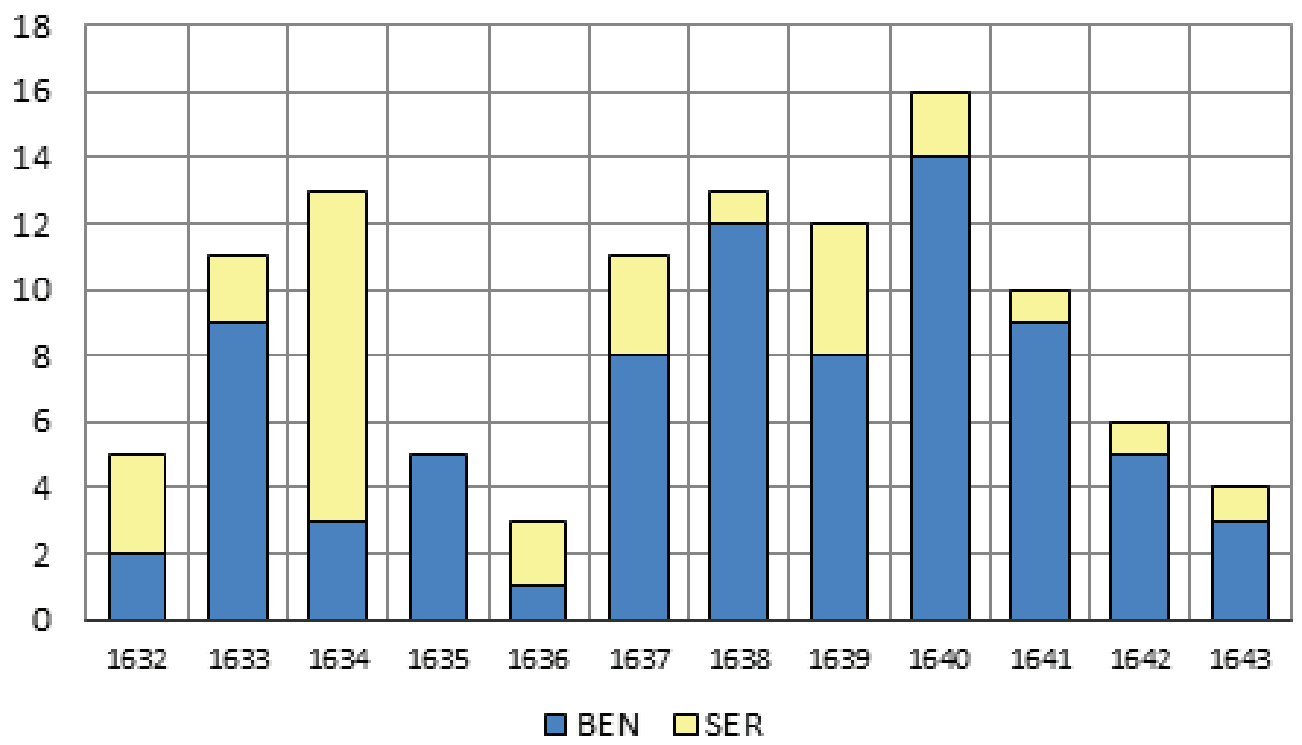

Tras un fuerte inicio (11 provisiones en 1633) el sistema se acrecentó entre 1637 y 1641, etapa bien problemática, coincidente con las más radicales reformas de Olivares y la rebelión de Portugal. Y aunque la desaparición del valido marcó un descenso, la fórmula del beneficio se fue consolidando en los años sucesivos.

\section{b) 2 etapa: 1644 a 1654. De la caída de Olivares a la "Cédula de Medios"}

En 1644, restaurada la Cámara de Indias, la legislación comenzó a distinguir entre cargos con jurisdicción aneja, otros poseedores en menor grado y otros carentes de ella, pues juristas y teólogos rechazaron radicalmente la provisión por dinero de todo empleo que conllevara potestad judicial, como eran los de justicia y gobierno. Respecto a los hacendísticos, se aceptó su continuidad como oficios "beneficiables" pues su competencia jurídica se limitaba a pleitos tocantes a la Hacienda y corrían menor riesgo de venalidad al carecer de la jurisdicción ordinaria que tenían magistrados, alcaldes mayores y corregidores.

Pese a ello, cuando en 1648 la Corona benefició la contaduría de la caja de Castrovirreina por 23.000 reales, el Consejo insistió en su disconformidad pero el rey declaró no poder renunciar a este medio. Así pues, la Cámara de Indias negoció 89 cargos de Hacienda entre 1644 y 1654 (19 de tribunales de cuentas) por un valor de 470.050 pesos, mientras que proveyó sólo 16 por méritos, según indica el gráfico IV: 


\section{Gráfico IV}

Provisiones de real hacienda (1644-1654)

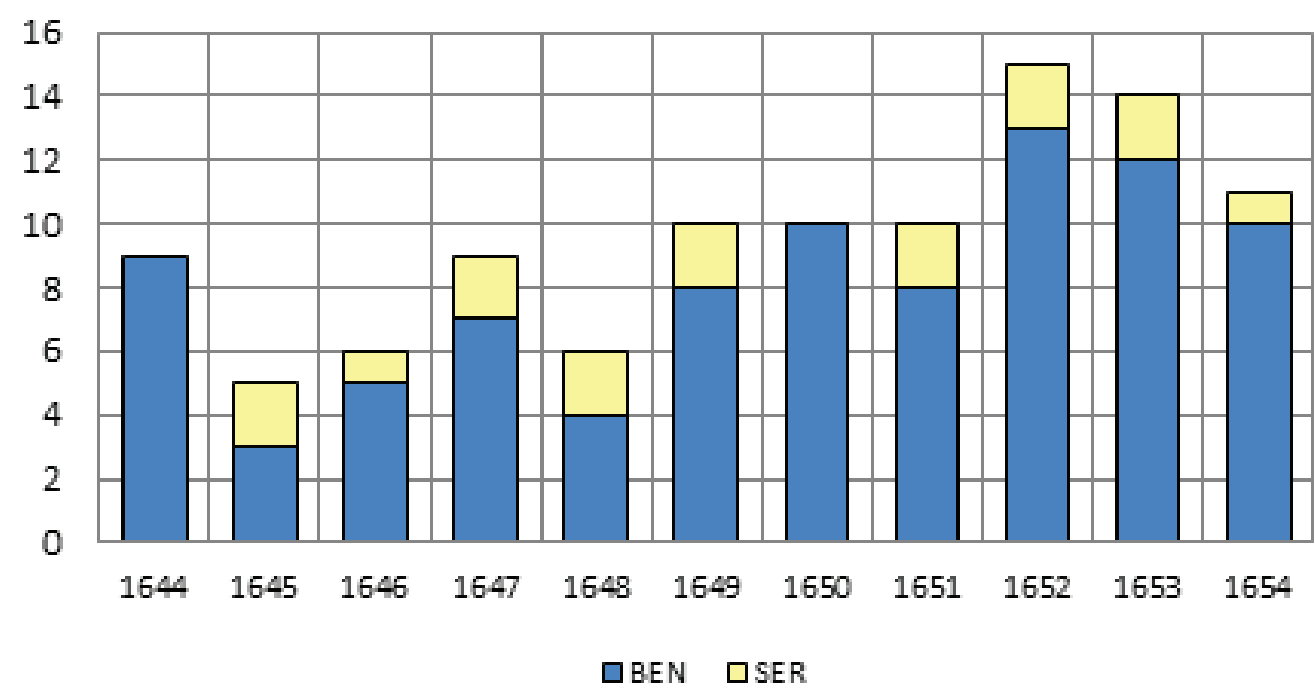

La continuidad queda demostrada, con una ligera tendencia alcista desde 1649 que afectó al número de transacciones y también al aumento sustancioso de los ingresos, superando el monto global de la etapa precedente.

\section{c) $3^{\text {a }}$ etapa: 1655 a 1660. La aplicación de la "cedula de medios"}

Hasta entonces la provisión en propiedad de los cargos de hacienda estaba limitada a los organismos peninsulares pues las autoridades indianas nada más podían hacer nombramientos interinos, pero en 1654 una nueva normativa posibilitó su adquisición en Indias por la denominada "cédula de medios". Como ampliamente justifica el documento, la necesidad imperiosa de fondos del Erario peninsular determinó un conjunto de medidas drásticas en busca de ingresos, destacando en especial la conveniencia de nuevos remates de los cargos antes negociados, porque "muchos se vendieron y perpetuaron en menos precio de su justo valor", ordenando a virreyes y presidentes que

[...] admitan las pujas y posturas a los oficios que se hubieren beneficiado así por mi Consejo de las Indias y el de Cámara de ellas y por Juntas y Ministros particulares como por mis virreyes y otros ministros [...] desde el año pasado de 1626 hasta ahora $^{39}$.

${ }^{39}$ Punto 5, Instrucción, 1-VI-1654 a las autoridades americanas [...] con que aumentar la Real Hacienda, AGI, Indiferente, 4329, L. 1, f. 183r-197v, en Muro Romero, 1978, pp. 63-64. 
Esta cédula sacaba los oficios de hacienda al mercado americano en subasta pública, y supuso de hecho y definitivamente su venta efectiva en Indias mientras la Cámara proseguía con sus nombramientos por beneficio o méritos. También permitía a las autoridades americanas hacer nombramientos beneficiados, con obligada confirmación posterior, como dice el monarca:

$[\ldots]$ han sido tantas $[\ldots]$ las necesidades $[\ldots]$ que $[\ldots]$ se han beneficiado por mi Consejo de Indias, por la Junta de Medios y por los diferentes ministros míos diversos oficios de oficiales de mi real Hacienda y Cajas donde se recoge; y siendo hoy mayores las necesidades que nunca, he resuelto conceder esta facultad a los dichos virreyes y presidentes de esas provincias, teniendo por bien que puedan beneficiar los oficios que vacaren o hubieren vacado de oficiales de mi Real Hacienda de todas las Cajas de ella, según y como hasta aqui se ha hecho y practicado en mi Corte ${ }^{40}$.

¿Qué respuesta tuvo la cédula de medios en los oficios de hacienda? Según nuestros cálculos, entre 1655 (inicio de ejecución) y 1660 (derogación), es decir, en los 6 años de vigencia, hubo 43 nombramientos con dinero (entre ventas y beneficios) negociados en 318.075 pesos, y otros 14 sólo ameritados. De los pecuniarios, 17 fueron en subasta pública en Indias por un importe de 177.375 pesos, mientras el donativo generó en España 140.700. Pese al importante ingreso, la aplicación general de la cédula de 1654 no cumplió las expectativas deseadas y la medida fue considerada desde la Corte como un fracaso ${ }^{41}$.

\section{Gráfico V: Distribución anual incluyendo la categoría venta (VEN)}

Provisiones de real hacienda (1655-1660)

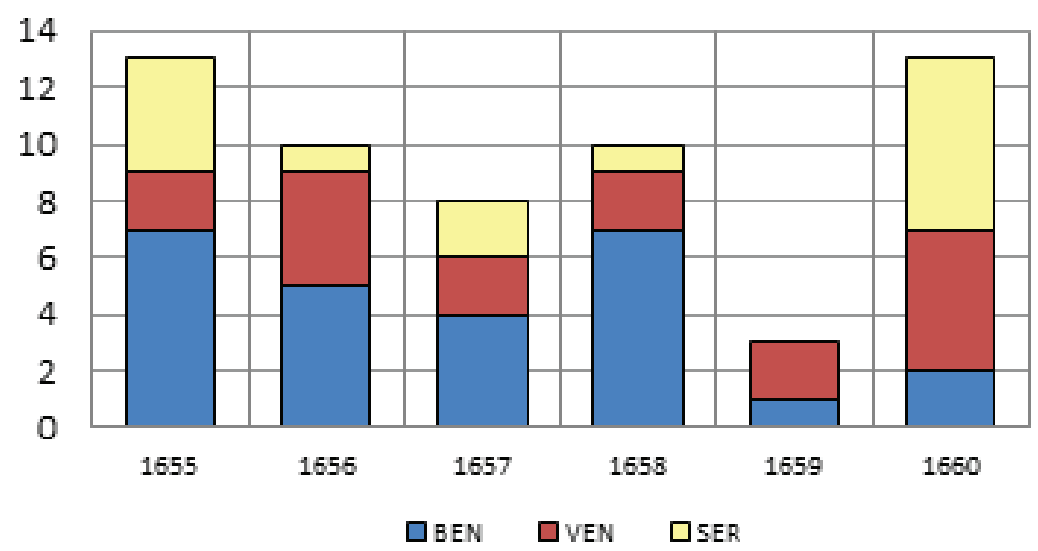

${ }^{40}$ El punto 14 de la Instrucción trata los Oficiales de las Cajas de Hacienda, Ibídem, pp. 64-65.

${ }^{41}$ Ingresos mucho más altos fueron generados por diversos puestos y oficios no específicos de Hacienda, como alguacilazgos, cabildantes, personal de Casas de la Moneda, notarías, etc.; como referencia: en el mismo periodo 10 cargos de alguacil mayor de caja real y tribunal de cuentas recaudaron 133.100 pesos. 
Ante el fallo de las expectativas previstas y los graves perjuicios creados, con fuertes quejas y denuncias de las autoridades americanas, el Consejo obtuvo del monarca la derogación de la "cédula de medios" en $1660^{42}$. Como razones se alegó: a) la pugna entre titulares anteriores y nuevos propietarios, que abonaron altas cuantías en los remates (el texto fue llamado "cédula de las venganzas"), b) la protección de las autoridades indianas a individuos incompetentes o inadecuados, c) la subida de salarios de los oficiales reales como una gran carga económica para la Hacienda, y d) el acceso al cargo de comerciantes, que lo aprovecharon para sus particulares negocios, amén de otras cuestiones, como el perjuicio a los indios por el aumento de los tributos ${ }^{43}$.

\section{d) $4^{\text {a }}$ etapa: 1661-1679. La estabilización del sistema}

En las dos décadas siguientes a la anulación de la "cédula de medios", la negociación prosiguió pero disminuyendo en número e ingresos, sobre todo en las transacciones en Indias (nulas entre 1673 y 1678 y escasas en el resto). Sólo mediados los años 70 se aprecia un repunte gracias a los beneficios peninsulares, que coincide con la salida al mercado de los oficios de gobierno ante la grave situación del Erario peninsular. Sobre 115 nombramientos (20 de tribunales de cuentas), 92 generaron 520.354 pesos, repartidos entre 403.804 por 79 beneficios y 116.550 por 13 ventas.

\section{Gráfico VI: Cuantías anuales}

\section{Provisiones de real hacienda (1661-1679)}

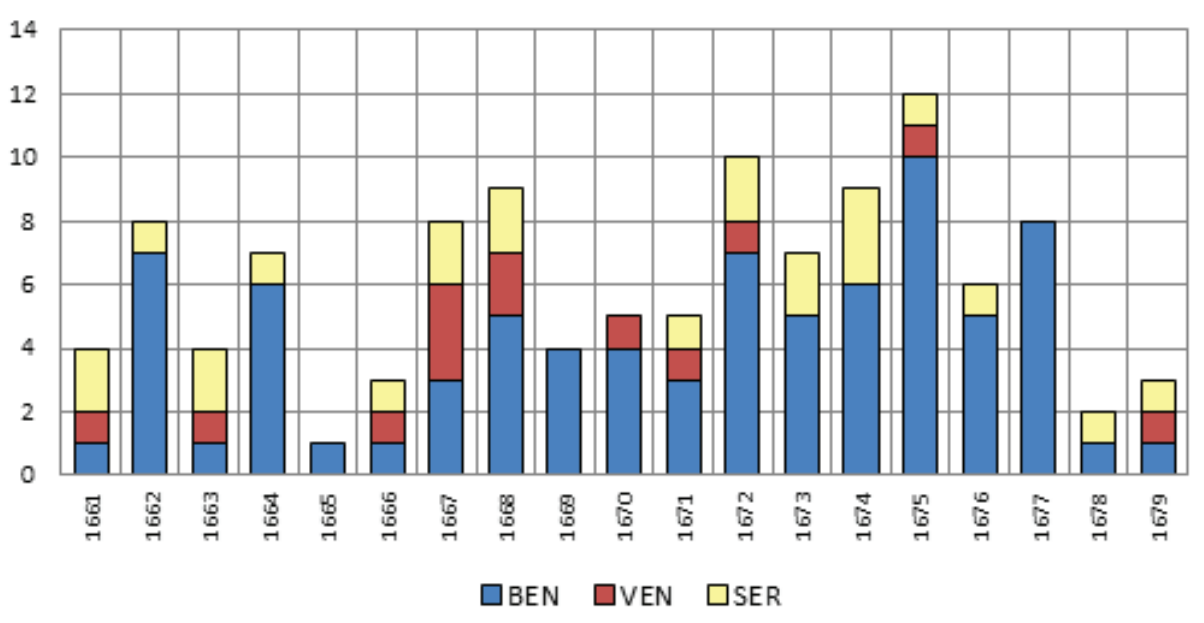

${ }^{42}$ Real Cédula de 18-III-1660 (AGI, Quito, 40, N. 57, entre otras) y Muro Romero, 1978, pp. 65-67; su texto dice: "no uséis ni permitáis se use de la referida [cédula] por vos ni por vuestros subdelegados, concediendo ni permitiendo se conceda ni practiquen las pujas, indultos, ni se beneficie ninguno de los medios ni oficios en ella expresados".

${ }^{43}$ Consulta del Consejo de Indias. Madrid, 27-II-1660. Ibídem, pp. 40-43. 
Pero, al parecer, la oferta no estaba cubierta pues en 1673 la Corona conocía que había más de 200 oficios vacos en general, sólo en la audiencia de México, que, aunque adecuadamente pregonados, no fueron adquiridos por sus altos precios 44 . Asimismo, en el ámbito del virreinato peruano consta que había compradores en 1669 dispuestos a rematar las plazas de oficiales reales, libres desde hacía tiempo, en buenas cantidades, pero la prohibición que anuló la "cédula de medios" en 1660 se lo impedía ${ }^{45}$. Y quizás también influyó en la retracción de los compradores la constatación de graves inconvenientes del sistema de renuncias, que el Consejo de Indias subsanó con específicos ajustes en la normativa, ante la delicada situación que se denunciaba así:

[...] teniéndose presente que la mayor parte de los oficios vendibles y renunciables [...] de ambos reinos del Perú y Nueva España están vacantes por defecto de renunciación o presentación, sin haber quien dé por ellos cantidad alguna, habiendo muchos tiempos que están en pública almoneda, y considerando que era el producto de estas renuncias unos de los principales ramos que mi Real Hacienda tenía en las Indias ${ }^{46}$.

\section{e) $5^{\text {a }}$ etapa: $1680-1690$. El auge del mercado}

Pero la urgente necesidad de caudales volvió a potenciar el mercado buscando la mayor rentabilidad, de modo que en 1680 se ordenó la ocupación en propiedad de todo puesto de caja real que quedara vacante, evitando a toda costa las interinidades porque no generaban ningún ingreso ${ }^{47}$. Y aún más rotundamente, en 1683 se estipuló que todo oficio renunciable que estuviese vaco se sacara a subasta y se rematara al precio que se pudiera conseguir ${ }^{48}$.

Así, entre 1680 y 1690 hubo un espectacular aumento de provisiones negociadas y de caudal ingresado, gracias a la oferta de cargos indianos del marqués de los Vélez, gobernador sustituto del presidente del Consejo, duque de Medinaceli. Cuando en 1687 Vélez fue titular también de Hacienda expandió aún más el mercado americano al negociar las magistraturas de audiencia indiana, puestos exclusivamente de justi-

${ }^{44}$ Informe del fiscal de la audiencia de México a la Reina gobernadora. México, 12-VI-1673. AGI, México 46, N. 51.

${ }^{45}$ Informe del contador del tribunal de cuentas de Lima, Juan de Saiceta Cucho, al arzobispo y virrey interino Melchor de Liñán y Cisneros, en carta de 25-IX-1669, que pasó al Consejo y generó la real cédula de 29-VI-1681 sobre beneficiar una relación de oficios vacos del virreinato peruano. En Confirmación del oficio de Simón de Sosa y Olivera, AGI, Charcas, 76, N. 20.

${ }^{46}$ Real Cédula de 21-II-1689 sobre renunciaciones de oficios, Muro Orejón, 1956, pp. 363-366. Por ella se anulaba una ley de la Recopilación y dos Reales Cédulas de 5-II y 30-XII-1674, que estipulaban la pérdida de sus oficios a manos de la real Hacienda para aquellos renunciantes cuya persona propuesta como sucesor no cumpliera las normas prescritas.

${ }^{47}$ Real Cédula de 13 de julio de 1680 dirigida a los oficiales reales de Nueva España, Guatemala, Islas Filipinas y de Barlovento, en Muro Orejón, 1956, pp. 101-102.

${ }^{48}$ Real Cédula de 20-IX-1683 sobre venta y uso de los oficios vendibles y renunciables que recoge otras tres de 1674, 1675 y 1678. AGI, Indiferente, L. 42, fol. 295v, Ibídem, pp. 200-201. 
cia, de modo que ya no hubo ningún freno al sistema de ventas y beneficios ${ }^{49}$. Tal se manifiesta en el gráfico VII:

\section{Gráfico VII}

Provisiones de real hacienda (1680-1690)

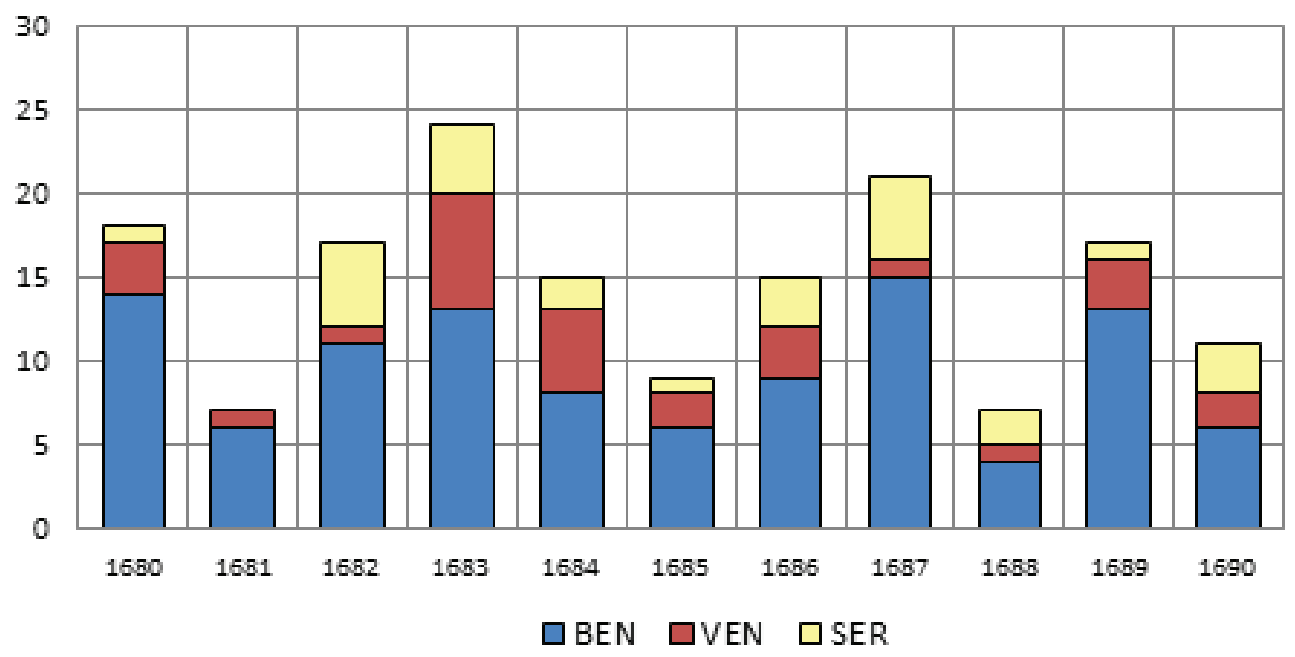

En efecto, superando todo lo anterior, entre 1680 y 1690 se alcanzaron las mayores cuantías del siglo en provisiones e ingresos por negociación pecuniaria, al reunir un total de 162 nombramientos (34 de tribunales de cuentas), de los cuales 134 generaron 748.562 pesos. Y aunque los cargos mercados en Indias sólo fueron 29, su importe alcanzó los 244.600 pesos.

En los años 1683, 1687, 1682 y 1689 se dieron las mayores cuantías del siglo, con record total en el primero: 24 provisiones, 20 negociadas y 107.850 pesos para la real hacienda.

\section{f) $6^{\text {a }}$ etapa: 1691-1700. El descenso de finales de siglo}

La última década de la centuria experimentó un marcado declive en transacciones e ingresos, quizás como consecuencia del excesivo negocio de años precedentes y del agotamiento de la oferta. Además, ya en 1689 surgió un intento de frenar el mercadeo de oficios (en gobierno, justicia y hacienda), como expresa el siguiente texto dirigido al virrey del Perú:

${ }^{49}$ Sobre cargos de audiencia véase BuRKholder-ChANDLER, 1985, y también SANZ TAPIA, 2007, pp. 44-47 y 52-53, como síntesis de fines del XVII. 
Habiéndose reconocido los inconvenientes que resultan a la recta administración de justicia de beneficiar los oficios y puestos de Indias en esta Corte, y que se seguirán los mismos de que vos lo continuéis en ese reino en los que son de vuestra provisión $[\ldots]$, he resuelto ordenaros y mandaros [...] no beneficiéis ocupación alguna que tenga administración de justicia o de hacienda, teniendo entendido que demás de mi desagrado será el más capital cargo de visita o residencia que se os hará ${ }^{50}$.

Sin embargo, no parece que tan taxativa orden tuviera mucha efectividad porque en 1691-1700 las provisiones negociadas continuaron aunque en tono menor. Hubo 65 nombramientos: 43 en la Corte, con beneficio de 242.517 pesos (menos de la mitad de la etapa anterior) y sólo 7 casos en Indias, por otros 88.200 pesos; en suma, marcado descenso en operaciones y ganancias.

\section{Gráfico VIII}

Provisiones de real hacienda (1691-1700)

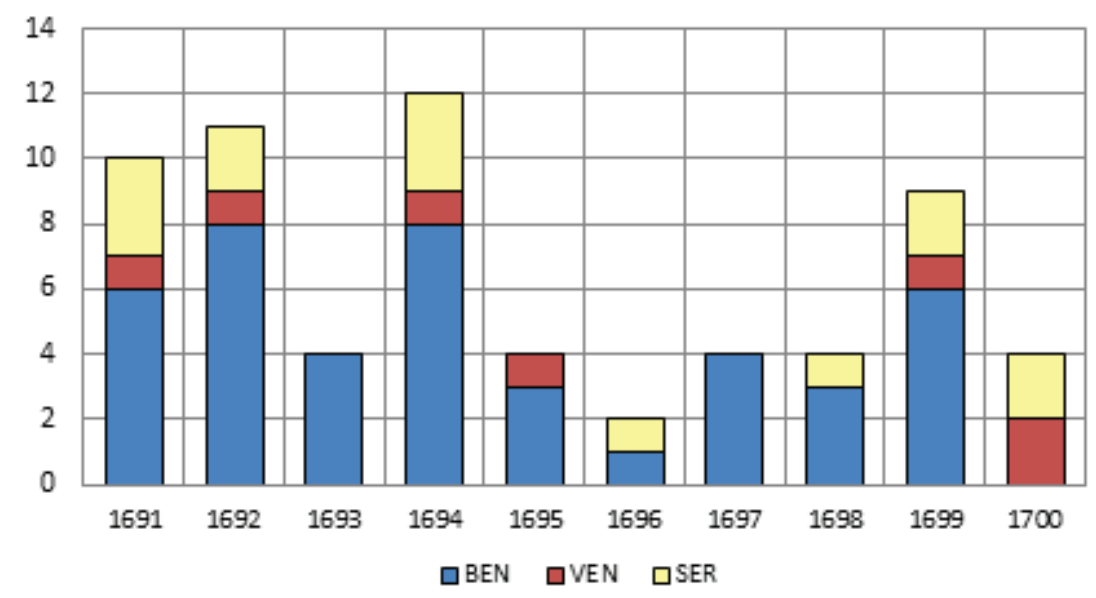

Cabe añadir que en este último decenio hubo dos factores incidentes: a) el intento de frenar el desmesurado crecimiento de la burocracia indiana, propiciado en parte por el desenfreno en la política de venta de oficios ${ }^{51}$, que provocó reajustes de las plantillas al dar preferencia a los funcionarios más antiguos frente a los nuevos (en la práctica sin demasiado éxito), y b) la variación de rentabilidad de los cargos por la descompensación entre el precio de compra y su valor real de lucro, creando una presencia de oficios vacos sin demanda en el mercado ${ }^{52}$, que, sin ser novedad, se acentuó en estos años.

\footnotetext{
${ }^{50}$ Real Cédula de 19-VI-1689 al virrey del Perú, AGI, Indiferente, 431, L. 43, f. 121, en Muro OreJóN, 1956, pp. 389-390.

${ }^{51}$ Tema tratado por Escobedo (1986, p. 88), referido al Tribunal Mayor de Cuentas de Lima y extensible al esquema general de los oficios de real hacienda de finales del siglo XVII.

${ }^{52}$ Herzog (1995, pp. 71-72) analiza los puestos de provincial, alguacil, escribano y procurador en Quito, ampliando esta conclusión a los cargos vendibles en general, hecho coincidente con la caída del beneficio de oficios de gobierno en esta década; véase SANZ TAPIA, 2009, pp. 68-74.
} 
Recapitulando, el análisis de las provisiones de hacienda muestra el uso mayoritario del sistema de venta/beneficio en el siglo XVII, superando siempre los nombramientos con dinero a los ameritados, en un porcentaje medio del $80 \%$, indicativo de que 4 oficios de cada 5 fueron dados por dinero. Momentos álgidos fueron la fase previa a la "cedula de medios" (1644-1654) con 84,8 \%, seguida por la década de 1680, con $83,2 \%$, y los casi 20 años precedentes $(1661-1679)$ con $80 \%$. El final del siglo, pese al descenso citado, superó las $3 / 4$ partes, $78 \%$, más que los años iniciales (163243) con 72,5; por el contrario, en la época de mayor apertura al mercado (1655-1660) sólo se alcanzó un 75,5\%, pese a la posibilidad de las compras en remate.

Tomando en cuenta cantidades, no porcentajes, resulta el gráfico IX:

\section{Gráfico IX}

Cargos negociados y ameritados por etapas

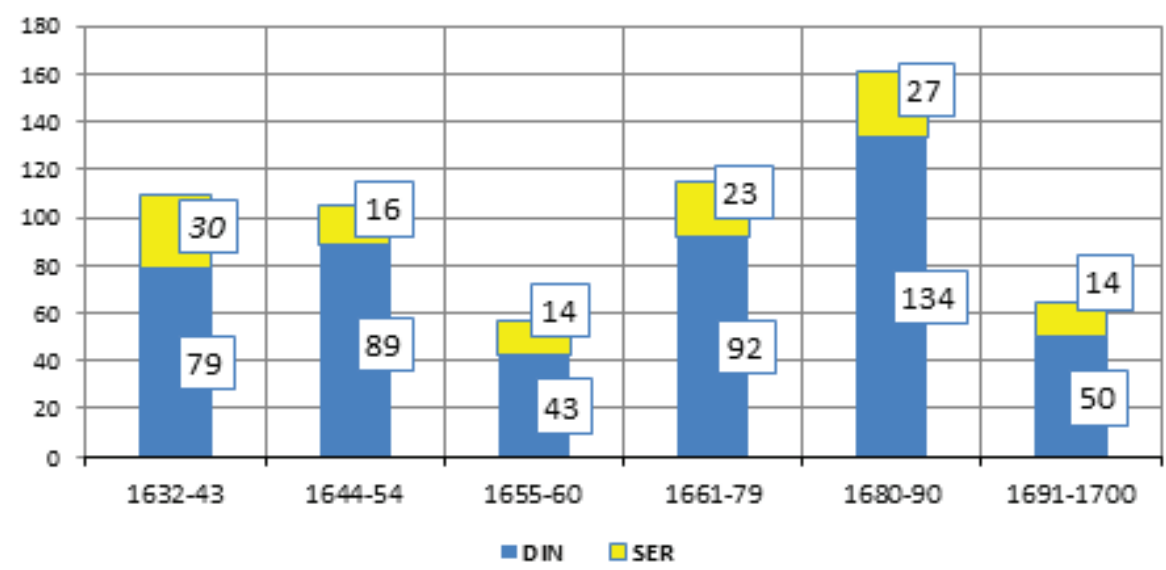

El periodo principal fue la década de 1680 , con la apertura general al mercado dispuesta por Medinaceli y sobre todo por Vélez, mientras la etapa anterior (años 60 y 70) debió la cuantía a su larga duración; contrariamente, las dos épocas de menos negocios (1655-1660 y 1691-1700) se explican porque en la primera la "cedula de medios" potenció compras de alto precio, merced a las subastas provocadas, pocas pero muy caras, y en década final hubo igualmente una selección de compra de cargos más rentables.

\section{LOS INGRESOS POR OFICIOS DE HACIENDA}

Los cálculos indican unos ingresos totales de 2.786 .258 pesos de 8 reales de plata por la negociación de 487 cargos de Hacienda indiana para el periodo 1632-1700. Por años, sólo a veces hubo proporción entre número de provisiones y sus desembolsos, pero se definen varias etapas, según gráfico $\mathrm{X}$ : 


\section{Gráfico X}

Ingresos anuales por cargos de real hacienda (1632-1700)

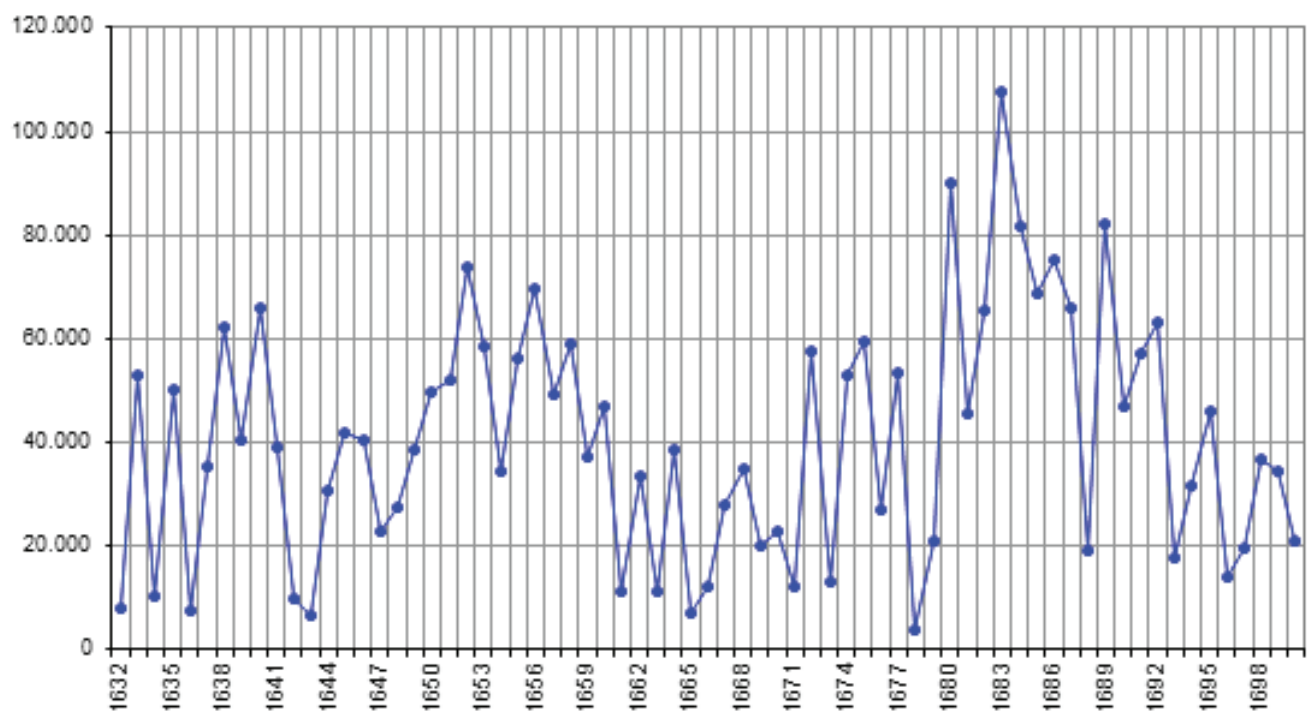

Hay varias fases: La primera abarca 1633-1641 superando cuatro veces los 50.000 pesos, con 1640 como cumbre (65.900); una segunda fue en 1650-1660, con 60.000 pesos de media (73.700 en 1652), tras la cual hay un descenso hasta 1672-1677 (55.000 de promedio); luego viene la culminación en 1682-1692 superando en 4 ocasiones los 80.000 pesos, con máximos en 1683 (107.850) y 1680 (90.200), para bajar en picos los años finales del siglo.

Relacionando estas cuantías con el número de cargos negociados en las seis etapas establecidas resultan unos valores medios por cargo ${ }^{53}$, que, independientemente de su categoría, podrían ser indicadores aproximados de la actitud del mercado. El gráfico XI así lo muestra, tomando como referencia la media general del siglo, que resultó de 5.721 pesos:

${ }^{53}$ No es posible incluir aquí el estudio de las valoraciones independientes de cada oficio en las diferentes audiencias por varias razones: a) muchas veces el nombramiento es indefinido ("oficial real"), b) son frecuentes los intercambios de puestos entre oficiales reales, c) abundan las ofertas plurales, es decir, una única cantidad para varios oficios al tiempo, y d) sobre todo porque la diversidad de puestos (factor, veedor, contador, tesorero, contadores diversos de tribunales, supernumerarios y futurarios) y lugares hace que ese análisis detallado (con los necesarios gráficos) suponga una extensión del texto bastante superior a lo establecido en la normativa de la revista. 


\section{Gráfico XI}

Ingresos y cuantias medias por etapas

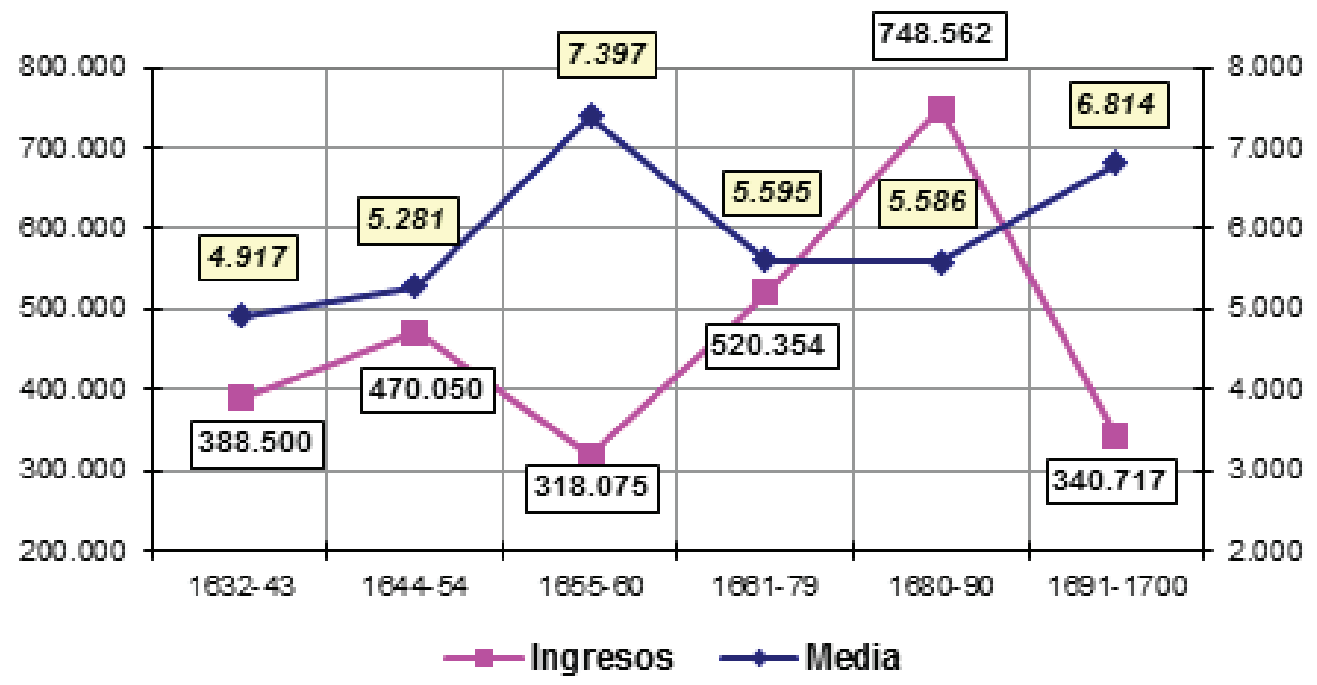

Mientras en las dos primeras etapas y en 1661-1679 ambas variables se corresponden, en las restantes sucede lo contrario. Así, durante la "cédula de medios" el monto generado fue el menor mientras el precio medio resultó el máximo, 7.397 pesos, indicativo de cortas operaciones pero de alto coste, y otro tanto sucedió en la década final de la centuria, también con bajos ingresos y segunda media más alta. En cambio, en los años 1680-1690 se alcanzó el mayor caudal y la media quedó ligeramente inferior a la general, situación que puede suponer mayoría de compras de precios más moderados.

Comentando brevemente cada periodo: En 1632-43 puede destacarse que los primeros cargos oficialmente dados por dinero fueron la tesorería de Zacatecas en 5.000 pesos para Domingo de Aldape, y el puesto de factor-veedor de La PlataPotosí para Cristóbal García Ramón en 3.000, aunque el oficio más costoso resultó la tesorería de Cartagena en 1635 (17.000 pesos) para Pedro Cordero de Cantillana, sargento mayor con gran carrera militar ${ }^{54}$.

En la fase siguiente (1644-54) el donativo más elevado fueron 30.000 pesos que Andrés del Rosal dio por una contaduría del tribunal mayor de México para futura

\footnotetext{
${ }^{54}$ Aldape era un capitán español que prefirió el puesto de hacienda a otro militar en Panamá, pues se valoraron sus servicios de guerra, AGI, Contratación, 5789, L. 1, F. 114-116; García Ramón era otro capitán español, AGI, Contratación, 5793, L. 2, f. 94v-96v.; donativo en ScHäFER, 2003, II, p. 169, nota 549, y Konetzke, 1953, II, $1^{\circ}$, p. 340. Cordero, natural de Jerez de la Frontera (Cádiz), había servido en la Armada del Mar Océano, Araya, Gibraltar y Brasil, AGS, DGT, In-1º, leg. 10, f. 171 v., y AGI, Indiferente, 111, N. 187: méritos.
} 
ocupación de su hijo Andrés del Rosal y Ríos, aún menor de edad para ejercer ${ }^{55}$. De 1655 a 1660, mientras tuvo vigencia la "cédula de medios", el mayor desembolso fueron otros 30.000 pesos por la tesorería de La Plata y Potosí, que Francisco Antonio Pita Castrillón adquirió en remate en 1659, seguido por 20.000 que Francisco de Oroz y Romeriño pagó en 1660 por la tesorería de Huancavelica ${ }^{56}$.

El largo periodo entre 1661 y 1679 también ofreció elevadas cuantías, en concreto 24.000 pesos dados en 1677 por el quiteño Alonso Pérez Castellanos para ser contador supernumerario del tribunal mayor de Lima, cantidad seguida en dos ocasiones por otros 20.000, a cargo de Francisco de Nestares y Prado por la contaduría de La PlataPotosí, en 1672, y por Andrés de Madariaga y Gaviria en 1674, quien compró la plaza de contador de cuentas del tribunal mayor de Lima para sí o para quien casare con su hija María ${ }^{57}$.

Durante la etapa de auge (1681 a 1690), como cuantías mayores están 20.000 pesos por una contaduría del tribunal de Lima en 1686 para el principal agente y traficante de cargos, Diego de Villatoro, quien no pensaba ejercer sino venderla al mejor postor; otros 17.200 por la tesorería del Cuzco, ganada en remate por Miguel Hurtado de Mendoza en 1690, y 17.000 más en 1681 por la contaduría cuzqueña para Juan Antonio Fernández de Guevara ${ }^{58}$.

En el postrer decenio, pese al descenso general, hubo abonos muy altos, con el record, 36.000 pesos, por una plaza supernumeraria de contador mayor del tribunal de México, que dio en 1691 el mercader sevillano Manuel José de Flores Manrique, y tres abonos más de 20.000, dos por idénticos puestos en el tribunal de cuentas de Lima (para Pedro Camacho del Corro y Segarra y José Saenz de Aguirre), y el tercero por la contaduría de cuentas del mismo lugar a favor de Diego José Quintello de Guzmán ${ }^{59}$.

${ }^{55}$ Título en AGI, Indiferente, 456, L. A27, ff. 344-348v.; ejerció entre 1652 y 1675; el padre había sido contador de las cajas de Acapulco y Guadalajara.

${ }^{56}$ En 1660 Pita se metió en largo pleito con el también tesorero Andrés de Bustamante Aguilar por la confirmación del título; ejerció entre 1659 y 1674, cuando renunció en su hermano Jacinto para ejercer el corregimiento de Trujillo del Perú; era hijo de Francisco Pita Castrillón, fundador de la Casa de la Moneda de Lima. AGI, Charcas, 74, N. 13, y el pleito en AGI, Escribanía, 849B. Oroz y Romeriño era criollo y ejerció en 1662-69; la confirmación del oficio está en AGI, Lima, 190, N. 23.

${ }^{57}$ Pérez Castellanos, alcalde de Quito y luego caballero de Santiago, contaba importantes servicios por parte del abuelo materno y además manejaba grandes capitales como mercader de oro y plata, por lo cual no extraña su relación con el agente Diego de Villatoro, quien figuraba como su podatorio, AGI, Contratación, 5795, L. 1, f. 169-171, beneficio en AGI, Contaduría, 235. Nestares era sobrino del presidente de la Audiencia de Charcas, Francisco Nestares Marín (la confirmación en AGI, Charcas, 74, N. 13, después de largo pleito con José de Arenas, otro aspirante). Madariaga era mercader, cónsul y diputado del comercio limeño, AGS, DGT, In-1 ${ }^{\circ}$, leg. 21, f. 202 v., y AGI, Contaduría, 235.

${ }_{58}$ Villatoro contaba con el favor de la Cámara de Indias por sus generosos préstamos y donativos, tanto a la real Hacienda como a particulares, hasta tal punto que se le dio facultad de nombrar personas en doce cargos de gobierno indiano, amén de otras prebendas similares; sobre el personaje vid. SANZ TAPIA, 2009, pp. 106-111. Hurtado era criollo peruano, AGI, Contaduría, 235. Fernández de Guevara, también criollo, compró el cargo en remate. Título y confirmación en AGI, Contaduría, 235.

${ }^{59}$ Flores Manrique no llegó a tomar posesión pese a que el cargo reunía varias prerrogativas, como juro de heredad, AGI, Contaduría, 235. Camacho era criollo potosino, AGS, DGT, In-24, ff. 172-322; Sáenz era español y primo del cardenal Aguirre, que abonó parte del dinero, Ibídem; y Quintello era criollo limeño y caballero de Alcántara, AGS, DGT, In-24, ff. 172-85. 


\section{REPARTO POR AUDIENCIAS Y ORIGEN DE LOS PROVISTOS}

Sobre 142 cargos de cajas reales y tribunales de cuentas de las 11 audiencias existentes, el cuadro siguiente muestra la distribución de las 621 provisiones localizadas, indicando provisiones totales, negociadas e ingresos:

\begin{tabular}{|l|c|l|l|l|}
\hline Audiencia & Cargos & Prov. Total. & Negociadas & Pesos \\
\hline México & 25 & 143 & 121 & 814.474 \\
\hline Guadalajara & 11 & 40 & 31 & 146.300 \\
\hline Guatemala & 7 & 28 & 26 & 77.600 \\
\hline Manila & 3 & 12 & 3 & 10.500 \\
\hline Santo Domingo & 18 & 88 & 58 & 177.367 \\
\hline Panamá & 4 & 18 & 13 & 70.500 \\
\hline Santa Fe Bogotá & 18 & 77 & 53 & 289.687 \\
\hline Lima & 31 & 124 & 105 & 780.830 \\
\hline Quito & 8 & 31 & 25 & 135.100 \\
\hline Charcas-La Plata & 13 & 40 & 36 & 232.500 \\
\hline Santiago Chile & 4 & 20 & 16 & 51.400 \\
\hline Totales & $\mathbf{1 4 2}$ & $\mathbf{6 2 1}$ & $\mathbf{4 8 7}$ & $\mathbf{2 . 7 8 6 . 2 5 8}$ \\
\hline
\end{tabular}

Lógicamente, las audiencias virreinales presentan cantidades superiores en provisiones y transacciones, México con 121 casos negociados de 142 totales y Lima con 88 sobre 106 dan casualmente el mismo porcentaje (84,67\%), yendo luego Santo Domingo con 58 sobre 88 posibles $(66 \%)$. No obstante, los porcentajes superiores correspondieron a Guatemala $(92,9 \%)$ y Charcas $(90 \%)$, con un predominio casi absoluto de oficios conseguidos por dinero. En el plano contrario estaba Manila, cuyos puestos sólo 3 veces se negociaron en propiedad, ya que lo habitual era el interinato o la ocupación por méritos.

En desembolsos, la mayor inversión fue para la audiencia mexicana con 814.474 pesos, cantidad que suponía el $29,2 \%$ del total, y luego la limeña, inmediata, con 780.830 pesos y el $28 \%$, seguida de los 289.687 de Santa Fe de Bogotá (10,4 \%), tres primeros puestos lógicos, tanto por su importancia como ser las sedes de los tribunales mayores de cuentas. Mínimos ingresos aportaron al Erario peninsular Santiago de Chile y sobre todo Manila, en razón de los escasos puestos existentes y del exiguo atractivo para los aspirantes.

Finalmente, se añaden una breve referencia sobre los oficiales provistos, aunque, por diversos motivos, no todos llegaron a ejercer el oficio. Los 621 nombramientos corresponden a 540 titulares $^{60}$, pues a veces uno mismo tuvo dos o más puestos, por

${ }^{60}$ Aparte de que el provisto ejerciera, por diversas circunstancias, un oficio distinto del designado (situación muy frecuente), buen número de títulos indican la posibilidad de optar por varios cargos, habitualmente por el primero que vacara, porque el comprador quería asegurar la rentabilidad de su 
ascenso de categoría o simple cambio de cargo o lugar. Del conjunto de provistos hay localizados 496 individuos $^{61}$ (el $92 \%$ ), siendo 281 españoles (con 334 provisiones) y 223 criollos (con 248 puestos), cuyo acceso indica el gráfico XII:

\section{Gráfico XII}

Provisiones según origen

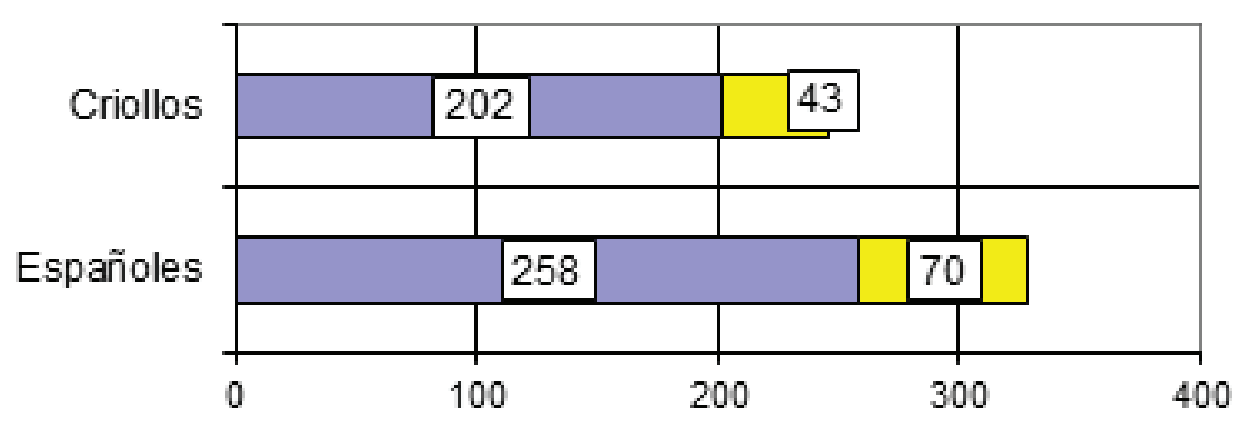

$\square$ Con dinero $\quad$ QSin dinero

De los 334 nombramientos de españoles, sólo 70 fueron sin dinero, mientras que 258 se lograron por transacción mercantil; respecto a los criollos, 43 de sus 248 provisiones fueron por méritos/servicios y 202 negociadas. Esto significa que los españoles consiguieron el $84 \%$ de sus cargos mediante desembolso pecuniario y los americanos el $90 \%$, porcentajes elevadísimos que testimonian cómo la vía del donativo o la compra (ésta sólo en Indias y de forma temporal) eran casi las únicas alternativas para ejercer un puesto de oficial de hacienda. No obstante, es preciso recordar que los titulares de donativo (que eran el $65 \%$ del total) también contaban con un expediente meritorio ante la Cámara de Indias, requisito que era cumplido por 201 españoles y 143 americanos.

En cuanto al importe de donativos y compras, el dinero de manos criollas sumó 1.226.091 pesos, esto es, el $44 \%$ del total, cuantía elevada pero a cierta distancia del gasto de los españoles, 1.430 .667 pesos, que hacían el $51 \%$. Es interesante destacar que el mayor desembolso entre americanos lo hicieron los nacidos en la audiencia limeña con 303.580 pesos gastados en 50 cargos, seguidos de los mexicanos con 201.974 pesos por otros 35 , y después los neogranadinos con 119.975 pesos invertidos en 20 puestos más.

gasto frente a las abundantes futuras existentes. Por ello, los reiterados cambios de puesto de un titular en su misma Caja o Tribunal Mayor complican la investigación extraordinariamente, al no resultar entonces bien especificada su exacta categoría.

${ }^{61}$ Hay 36 provistos no localizados, que suman 39 provisiones $(6,3 \%$ del total), de ellas 11 por servicios, 27 pecuniarias y 1 no conocida. Su gasto: 129.500 pesos (4,6 \% del ingreso total). 
Tanto el número de provistos como de provisiones, cargos negociados e incluso cuantías abonadas guardan una cierta proporción entre los nativos de ambas orillas del Atlántico aunque ligeramente superior en los peninsulares. No obstante, los datos revelan el alto porcentaje de criollismo, en torno al $40 \%$ (en puestos, titulares y transacciones) existente en la administración de la Hacienda indiana durante el siglo XVII, aspecto relevante, sobre todo teniendo en cuenta que eran nombramientos vitalicios en propiedad.

Es claro que para los criollos la adquisición en propiedad de un puesto de oficial real significaba un ascenso social importante y unas posibilidades de afirmación personal y grupal en su entorno y ante las autoridades peninsulares, además de un negocio sin duda bien rentable. Por otra parte, la ocupación del mismo cargo mediante dinero por un español parece indicar en principio una evidente intención de enriquecimiento, proyecto que el ejercicio del cargo americano y la estancia indiana podría derivar hacia la permanencia indefinida en su nueva tierra. En definitiva, parece lógico suponer que muchos de ellos echaran raíces familiares y sociales, se quedaran en América y se criollizaran.

\section{CONCLUSIONES}

Entre 1632 y 1700 se dieron en propiedad 621 puestos de oficiales de hacienda de Indias, de los cuales 487 fueron obtenidos por dinero y 124 sólo por méritos/ servicios. En porcentaje, el 78,4 \% frente al $20 \%$ respectivamente, cuantías que suponen una proporción de 4 a 1 y muestran cómo la negociación pecuniaria (por beneficio o venta) fue la fórmula dominante en el siglo XVII, acrecentándose en las dos décadas finales. El mayor número de provisiones mercadeadas correspondió al ámbito de la audiencia mexicana (121 casos) y luego a la limeña (con 105), ambas con una fuerte demanda de las contadurías de los tribunales mayores en plazas futuras y sobre todo supernumerarias, muchas tasadas por encima de 12.000 pesos, algunas en más de 20.000 e incluso los 30.000 pesos que abonó Andrés de Rosal y Ríos en 1645 por la futura de contador del tribunal mexicano, donde ejerció entre 1652 hasta su muerte en $1675^{62}$. De todos modos, al margen del origen, los donantes razones tenían poderosas razones (sociales, económicas o políticas) para hacer desembolsos tan considerables, no siendo la menor "disfrutar de su inversión con un rendimiento vitalicio en forma de ocupar una plaza de prestigio y un sueldo nada despreciable"63

El importe de las 487 transacciones sumó 2.786 .258 pesos de plata de 8 reales. El monto del gasto de los españoles fue 1.430 .667 pesos $(51 \%)$ en tanto que el criollo fue 1.226 .091 pesos (44\%), dato que presupone una alta valoración del potencial económico criollo. Es destacable el mayor desembolso de los nativos peruanos para alcanzar también el máximo de puestos fiscales, aspecto que se repitió en su acceso a los cargos de gobierno también por beneficio a partir de $1686^{64}$. El abono de

\footnotetext{
${ }^{62}$ Título en AGI, Indiferente, 456, L. A27, ff. 344-348V.

63 Pietschmann, 1982, p. 24

${ }^{64}$ Sanz Tapia, 2009, pp. 133-138.
} 
donativo o la compra, más la obligada y elevada fianza, la media anata y otros gastos previstos o accidentales, exigía reunir elevadas cantidades, no siempre disponibles por el interesado, lo que conllevó fuertes e inexcusables préstamos, que repercutieron en la dinámica económica del cargo y de su propietario. Con frecuencia, la documentación manifiesta abierta o veladamente la existencia de redes de intereses en torno al oficio así como las relaciones de clientelismo que posibilitaban su ejercicio, por vía de financiación, matrimonio o actividades ilegales (contrabando, extorsión o apropiación del numerario estatal).

Los 621 nombramientos correspondieron a 540 titulares, de los cuales hay identificados 504 (el $93 \%$ ). Eran 281 españoles (con 334 provisiones, 258 negociadas) y 223 criollos (con 248, de ellas 202 por dinero), que en porcentajes globales hacen un 53,8 \% frente al $40 \%$. El dato aplicado al tema de la criollización de la administración americana indica un alto nivel de presencia en el ejercicio de la tarea hacendística y del control fiscal durante el siglo XVII, referencia hasta ahora desconocida. En cuanto a la continuidad del titular en el oficio, aparte de la transmisión familiar por renuncia, se ha constatado cierta vinculación, aunque eran frecuentes los cambios de puesto o de lugar, y también constan situaciones de paso del puesto fiscal a un cargo de gobierno, por lo general mediando dinero.

Finalmente, el mercadeo de cargos de hacienda tuvo importantes repercusiones. Para la administración americana, su adquisición por dinero abrió la puerta al uso de idéntica venalidad con los oficios de gobierno y justicia; por otra parte, permitió que aquellos puestos otorgados en América por subasta pública pasaran a ser tratados como "vendibles y renunciables, planteando una problemática compleja sobre la legalidad de su cesión patrimonial por la Corona. Y si bien los ingresos generados fueron un auxilio para la maltrecha Hacienda peninsular, también permitieron su ejercicio fiscal a una mayoría de gentes económicamente solventes aunque de dudosos méritos. También el sistema fue un magnífico modo de ascenso social, y en especial permitió a los criollos la posibilidad de alcanzar un puesto de prestigio y responsabilidad en el esquema colonial americano.

\section{REFERENCIAS BIBLIOGRÁFICAS}

ANDRIEN, Kenneth

1982 "The sale of fiscal offices and the decline of royal authority in the Viceroyalty of Peru, 1633-1700". Hispanic American Historical Review. Durham. vol. 62: 1, pp. 49-71.

BerTRAND, Michel

1999 Grandeur et misères de l'office, les officiers de finances de NouvelleEspagne, XVIIème y XVIIIème siècles. Paris. Publications de la Sorbonne.

BurkHolder, Mark A. y Chandler, D.

1984 De la impotencia a la autoridad. La Corona española y las Audiencias en América (1687-1808). México. Fondo de Cultura Económica. 
Donoso, Alberto

2008 "Organización y funcionamiento administrativo y contable de la Real Hacienda de Indias en tiempos de los Austrias a la luz de la legislación aplicable". De Computis: Revista Española de Historia de la Contabilidad. $\mathrm{n}^{\circ}$ 9, pp. 50-98. www.decomputis.org/

EsCOBEDO, Ronald

1986 Control fiscal en el virreinato peruano. El Tribunal de Cuentas. Madrid. Alhambra.

Herzog, Tamar

1995 La administración como un fenómeno social: La justicia penal de la ciudad de Quito (1650-1750). Madrid. Centro de Estudios Constitucionales.

KONETZKe, Richard

$1953 \quad$ Colección de documentos para la Historia de la formación social de Hispanoamérica 1493-1810. T. II: 1. Madrid. Instituto Jaime Balmes. Consejo Superior de Investigaciones Científicas.

Muro Orejón, Antonio

1956 Cedulario Americano del siglo XVIII. Tomo I. Sevilla. Escuela de Estudios Hispanoamericanos.

Muro Romero, Fernando

1978 "El beneficio de oficios públicos con jurisdicción en Indias. Notas sobre sus orígenes". Anuario de Estudios Americanos. Sevilla. vol. XXXV, pp. 1-67.

PARRY, J. H.

1953 The sale of public offices in Spanish under the Hapsburgs. BerkeleyLos Angeles.

Pietschmann, Host

1982 "Burocracia y corrupción en Hispanoamérica colonial. Una aproximación tentativa". Nova Americana. Torino. n ${ }^{\circ}$ 5, pp. 9-37.

RECOPILACIÓN

1973

[1681] Recopilación de Leyes de los Reynos de las Indias. Madrid. Cultura Hispánica.

Román, Alberto Yali

1972 "Sobre Alcaldías Mayores y Corregimientos. Un ensayo de interpretación", Jahrbuch für Geschichte Lateinamerikas. Colonia. $\mathrm{n}^{\mathrm{o}}$ 9, pp. 1-39.

SÁnchez Bella, Ismael

1968 La organización financiera de las Indias (siglo XVI). Sevilla. Escuela de Estudios Hispanoamericanos. 
SAnz TAPIA, Ángel

2007 "El proceso de venta y beneficio de cargos indianos en el siglo XVII”. En Ruiz Rivera, Julián y Sanz Tapia, Ángel (coords.). La venta de cargos y el ejercicio del poder en Indias. León. Universidad de León, pp. 33-57.

2009 ¿Corrupción o necesidad? La venta de cargos de gobierno indianos bajo Carlos II (1674-1700). Madrid. Consejo Superior de Investigaciones Científicas.

SCHAFËR, Ernesto

2003 El Consejo Real y Supremo de las Indias. Salamanca. Junta de Castilla y León y Marcial Pons [Reedición de Sevilla, 1935 y 1947].

Tepaske, John Jay

1976 La Real Hacienda de Nueva España: la Real Caja de México (15761816). México. Instituto Nacional de Antropología e Historia.

Tomás y Valiente, Francisco

1972 La venta de oficios en Indias (1492-1606). Madrid. Instituto de Estudios Administrativos.

1973 "Notas sobre la venta de oficios públicos en Indias". III Congreso Internacional de Historia del Derecho Indiano. Madrid. Instituto de Estudios Jurídicos, pp. 377-421.

1976 "Ventas y renuncias de oficios públicos a mediados del siglo XVII". Actas del IV Congreso Internacional de Historia del Derecho Indiano. Publicadas en Revista de la Facultad de Derecho de México. México. n²6, pp. 725-753. 